This item was submitted to Loughborough's Research Repository by the author.

Items in Figshare are protected by copyright, with all rights reserved, unless otherwise indicated.

\title{
Combined bounce, pitch, and roll dynamics of vehicles negotiating single speed bump events
}

\section{PLEASE CITE THE PUBLISHED VERSION}

PUBLISHER

Professional Engineering Publishing / @ IMECHE

VERSION

VoR (Version of Record)

LICENCE

CC BY-NC-ND 4.0

\section{REPOSITORY RECORD}

Azman, M., P.D. King, and Homer Rahnejat. 2019. "Combined Bounce, Pitch, and Roll Dynamics of Vehicles Negotiating Single Speed Bump Events”. figshare. https://hdl.handle.net/2134/4733. 
This item was submitted to Loughborough's Institutional Repository (https://dspace.lboro.ac.uk/) by the author and is made available under the following Creative Commons Licence conditions.

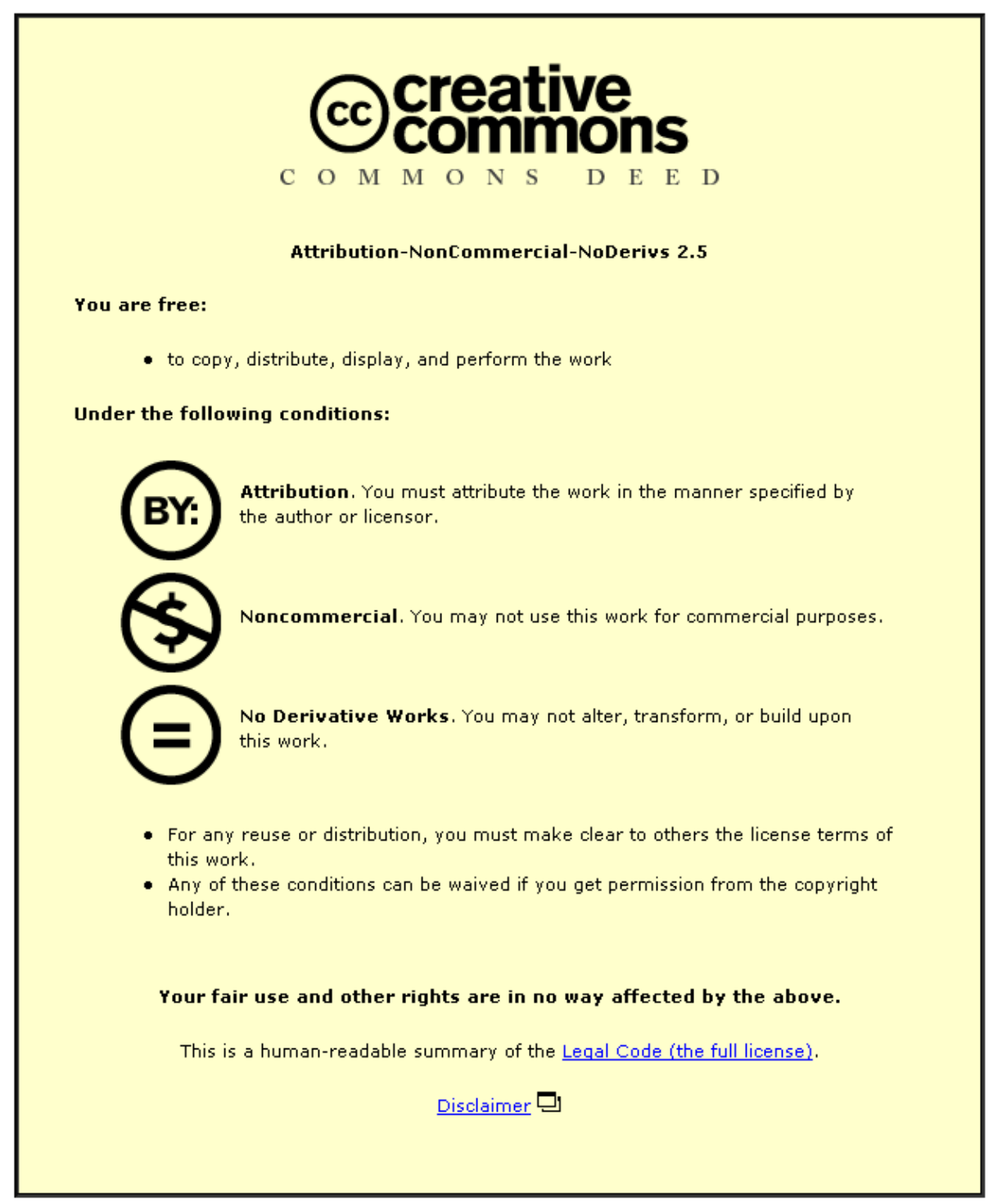

For the full text of this licence, please go to: http://creativecommons.org/licenses/by-nc-nd/2.5/ 


\title{
Combined bounce, pitch, and roll dynamics of vehicles negotiating single speed bump events
}

\author{
M Azman, P D King, and H Rahnejat* \\ Wolfson School of Mechanical and Manufacturing Engineering, Loughborough University, Loughborough, \\ Leichestershire, UK
}

The manuscript was received on 9 February 2006 and was accepted after revision for publication on 1 November 2006.

DOI: 10.1243/1464419JMBD55

\begin{abstract}
This paper investigates vehicle dynamic response for the increasingly common manoeuvre over single speed bumps, which is a non-trivial complex motion. One major aim of the study is to investigate the effect of the anti-roll bar upon vehicle body dynamics, while negotiating such traffic calming features. Numerical predictions are made with an intermediate vehicle model, whose results conform well to the actual vehicle tests. These results seem to suggest that events caused by truncated speed bumps can have implications for design of anti-roll bars from a ride comfort viewpoint, over and above the usual requirements dictated by safe vehicle handling.
\end{abstract}

Keywords: vehicle dynamics, virtual work, intermediate vehicle modelling, pitch-plane and roll dynamics, anti-roll bar

\section{INTRODUCTION}

The general effects of driving and braking torques on vehicle pitch-plane dynamics are quite well known, but as Sharp [1] has pointed out even pitch-plane dynamics of a standard road car on a flat road due to transient effects is a non-trivial problem. However, the transient effect of braking and driving torques on a flat road has limited applications. With increasing use of traffic calming features, such as speed bumps both transient torque inputs and vertical road surface geometry play significant roles that are rather typical of intermittent driving conditions in an urban area. Intermittent throttle and braking is combined with discrete event road inputs, which significantly affect pitch-plane dynamics, including transient longitudinal load transfer, and dynamic vertical and longitudinal tyre force inputs to the front and rear suspensions. Azman et al. [2] studied the combined pitch-plane and vertical dynamics (bounce) of a vehicle, and in particular, the effect of antidive

*Corresponding author: Wolfson School of Mechanical and Manufacturing Engineering, University of Loughborough, Loughborough, Leichestershire LE11 3TU, UK. email: h.rahnejat@lboro.ac.uk and antisquat arms to counter the arising undesired transient effects. They showed that the effectiveness of these mechanisms is much reduced with any significant bounce motion of the vehicle and reduced time of manoeuvre. Their study included the use of a six-degree-of-freedom vehicle model, instead of the usual fairly detailed multi-body approach, but with realistic suspension kinematics and a non-linear load-dependent tyre model. This approach, termed intermediate modelling showed good conformance with vehicle tests [2]. The study, highlighted in reference [2], can be regarded as largely one of transient ride analysis. A natural extension of it is the inclusion of vehicle roll, for example, in negotiating single speed bumps. This brings about combined ride and handling under transient conditions, where the effect of anti-roll bar on the stability of the vehicle can be ascertained. This paper highlights such an approach, and ascertains the effectiveness of the intermediate modelling method by the degree of conformance of its predictions with actual vehicle tests under same manoeuvres.

\section{DESCRIPTION OF THE VEHICLE DYNAMICS MODEL}

The model is based on a six-degree-of-freedom rigid body model [2] with simplified generic representation 
of suspension kinematics. The model is developed so that it can assist in the study of vehicle dynamics on non-flat roads (e.g. with speed bumps). In this initial form, it excludes certain features of a real vehicle, which should be borne in mind. These are:

(a) structural flexibility, such as the torsional stiffness of the body/chassis;

(b) suspension compliance in camber, steer, caster, and in longitudinal and lateral directions;

(c) unsprung mass dynamics (such as that experienced in wheel-hop);

(d) capability to deal with short-wavelength road profile features;

(e) transience due to engine and transmission (assumes an infinitely variable transmission with only a maximum limit on power).

The vehicle model is divided into several main features: body dynamic, vehicle kinematics, suspension and steering system, and driveline and tyre. It also incorporates a basic driver model.

\subsection{Rigid body dynamics}

The model uses body-fixed coordinates (Fig. 1). The inputs are the 12 force components applied to the tyres

$$
\mathbf{F}_{\mathrm{T}}=\left[F_{x 1}, \ldots, F_{x 4}, F_{y 1}, \ldots, F_{y 4}, F_{z 1}, \ldots, F_{z 4}\right]^{\mathrm{T}}
$$

These forces are directly applied to the vehicle body. Because the unsprung mass is neglected, the resultant forces are directly 'transmitted' to the vehicle body structure. The state variables are

$$
\mathbf{x}=[U, V, W, p, q, r]^{\mathrm{T}}
$$

Mass centre translational and body angular velocities are used in body-fixed SAE axes. Other inputs include the aerodynamic force. However, due to relatively low speeds, the effect of aerodynamic forces has been neglected. The vehicle weight is an important input to the system, as

$$
\mathbf{F}_{\text {weight }}=M g \boldsymbol{k}
$$

where $\boldsymbol{k}$ is the unit vector of the global $z$-direction, relative to the vehicle coordinates. The anti-roll bar affects the vehicle body roll. However, if the road profile is to be included in the model, the roll moment in equation (4) is no longer valid and must include the effect of suspension vertical travel

Roll moment due to the stabilizer bar $=K_{\text {roll_coeff }}(\phi)$

Additional roll deflections due to road profile for both front and rear can be represented in a general form as (Fig. 2)

$$
\mathrm{d} \phi=\tan ^{-1}\left[\frac{Z_{\mathrm{rp}}}{\text { wheel_track }}\right]
$$

where $Z_{\mathrm{rp}}$ is the height difference between the left and the right tyre contact patches. Thus, the moments generated by the anti-roll bar are obtained by adding to the body roll angle as

$$
K_{\text {roll_coeff }}[\phi-\mathrm{d} \phi]
$$

Equations of motion are based on the standard Newton-Euler form as

$$
m\left(\dot{\mathbf{v}}_{G}^{\mathrm{rel}}+\boldsymbol{\omega} \times \mathbf{v}_{G}\right)=\Sigma \mathbf{F}_{\text {tyres }}+\mathbf{F}_{\text {weight }}+\mathbf{F}_{\text {stabilizer }}
$$

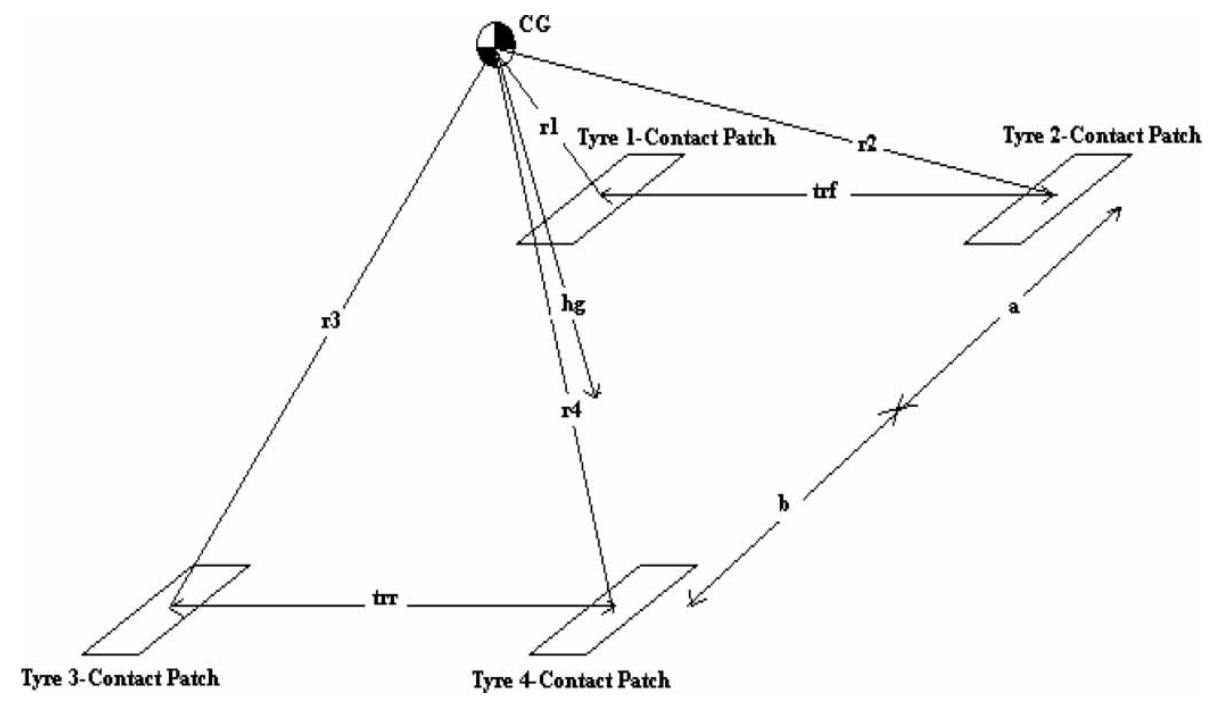

Fig. 1 Vehicle representation based on body-fixed coordinates 
The translational dynamics $\left(F=m a_{\mathrm{G}}\right)$ can be divided into three translational elements

$$
\text { Longitudinal dynamics: } \begin{gathered}
m \cdot(\dot{U}-V \cdot r+W \cdot q) \\
=F_{x}
\end{gathered}
$$

Lateral dynamics: $m \cdot(\dot{V}-W \cdot p+U \cdot r)=F_{y}$

Vertical dynamics: $m \cdot(\dot{W}-U \cdot q+V \cdot p)=F_{z}$

For rotational dynamics, the general equation is

$$
\mathbf{I}_{\mathrm{G}} \dot{\boldsymbol{\omega}}^{\mathrm{rel}}+\boldsymbol{\omega} \times\left(\mathbf{I}_{\mathrm{G}} \boldsymbol{\omega}\right)=\Sigma \mathbf{M}_{\mathrm{tyres}}
$$

where, the inertial matrix assumes lateral symmetry

$$
\mathbf{I}_{\mathrm{G}}=\left(\begin{array}{ccc}
\mathbf{I}_{x x} & 0 & -\mathbf{I}_{x z} \\
0 & \mathbf{I}_{y y} & 0 \\
-\mathbf{I}_{x z} & 0 & \mathbf{I}_{z z}
\end{array}\right)
$$

The equations can also be divided into three rotational elements $(L, M, N)$. These are

$$
\begin{aligned}
& \text { Roll moment: } \mathbf{I}_{x x} \dot{p}-\mathbf{I}_{z x} \dot{r}-\mathbf{I}_{y y} q r+\mathbf{I}_{z z} q r \\
& -\mathbf{I}_{z x} p q=L \\
& \text { Pitch moment: } \mathbf{I}_{y y} \dot{q}-\mathbf{I}_{z z} p r+\mathbf{I}_{x x} p r+\mathbf{I}_{x z} p^{2} \\
& -\mathbf{I}_{x z} r^{2}=M
\end{aligned}
$$

Yaw moment: $\mathbf{I}_{z z} \dot{r}-\mathbf{I}_{x z} \dot{p}-\mathbf{I}_{x x} p q+\mathbf{I}_{y y} p q$

$$
+\mathbf{I}_{x z} r q=N
$$

There are several ways of modelling dynamics of a vehicle. For a basic vehicle model, state-space approach can be used. However, for a higher level of complexity, which includes non-linear elements, the approach is no longer suitable. A combination of MATLAB and SIMULINK software are used, where $[U, V, W, p, q, r]$ are the states for the vehicle model.

The input consists of the outputs from the tyre forces, the aerodynamic force, the vehicle weight, and also the vertical reaction of the suspension system.

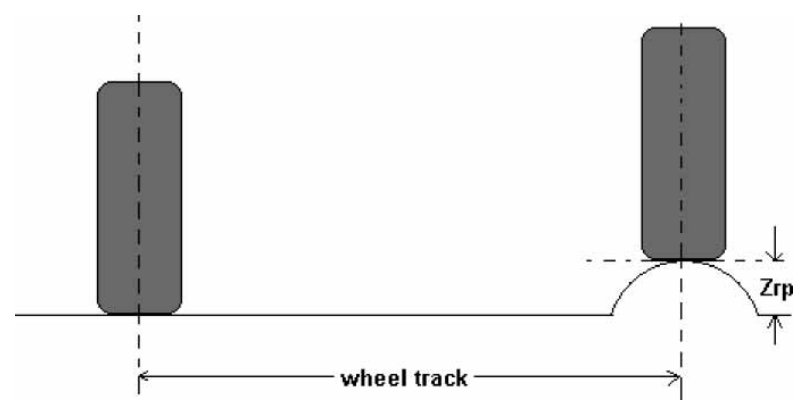

Fig. 2 Road profile effect on body roll
In order to establish the derivative equations, it is necessary to rearrange the equations of motion as follows

$$
\text { Longitudinal dynamics: } m \dot{U}=F_{x}-m(W q-r V)
$$

$$
\begin{aligned}
& \text { Lateral dynamics: } m \dot{V}=F_{y}-m(r U-p W) \\
& \text { Vertical dynamics: } m \dot{W}=F_{z}-m(p V-q U) \\
& \text { Roll moment: } \begin{aligned}
\mathbf{I}_{x x} \dot{p}-\mathbf{I}_{z x} \dot{r}= & M_{x}+\left(\mathbf{I}_{y y}-\mathbf{I}_{z z}\right) q r \\
& +\mathbf{I}_{z x} p q
\end{aligned}
\end{aligned}
$$

Pitch moment: $\mathbf{I}_{y y} \dot{q}=M_{y}+\left(\mathbf{I}_{z z}-\mathbf{I}_{x x}\right) p r-\mathbf{I}_{x z} p^{2}$

$$
+\mathbf{I}_{x z} r^{2}
$$

Yaw moment: $\mathbf{I}_{z z} \dot{r}-\mathbf{I}_{\mathrm{xz}} \dot{p}=M_{z}+\left(\mathbf{I}_{x x}-\mathbf{I}_{y y}\right) p q$

$$
-\mathbf{I}_{x z} r q
$$

\subsection{Vehicle kinematics}

The main purpose is to turn the local (vehicle-based) angular velocities into Euler angle derivatives and then integrate to find roll, pitch, and yaw angles. Euler angle derivatives are found in references $[\mathbf{3}, \mathbf{4}]$ as

$$
\begin{aligned}
& \dot{\theta}_{1}=\omega_{1}+\left(\omega_{2} \sin \theta_{1}+\omega_{3} \cos \theta_{1}\right) \tan \theta_{2} \\
& \dot{\theta}_{2}=\omega_{2} \cos \theta_{1}-\omega_{3} \sin \theta_{1} \\
& \dot{\theta}_{3}=\left(\omega_{2} \sin \theta_{1}+\omega_{3} \cos \theta_{1}\right) / \cos \theta_{2}
\end{aligned}
$$

Euler angles are used to rotate the local mass centre velocity into globals, which are then integrated to find the global $x, y, z$ coordinates of centre of mass. Vehicle accelerations are also found in both local and global coordinates, but only for postprocessing purposes.

\subsection{Suspension and steering}

Suspension calculation is based on the principle of virtual work, which includes the influence of suspension geometry, such as antidive characteristics and scrub effects. Consider the active forces and moments acting on the wheel/hub assembly, when the body is fixed, then virtual work can be written in the form

$$
F_{x} \delta x+F_{y} \delta y+F_{z} \delta z+F_{\mathrm{s}}(-\delta z)+T_{\mathrm{d}} \delta v=0
$$

Here, all the forces are acting on the wheel/hub assembly and the link reaction forces (ball-joints at the body connections) make no contribution. $F_{z}$ increases with tyre extension, but carries a large negative component due to the static load. Overall, this is negative, tending to zero as the tyre lifts off the road surface. Similarly, $F_{\mathrm{s}}$ would usually be negative, but increases as the suspension is expanded. The virtual work equation (23) is based on the bodyfixed coordinates and $z$ is the suspension deflection 
(vertical height change of the contact patch centre). This is considered as an independent variable. As the suspension is deflected, $\delta x$ and $\delta y$ (contact patch forward progression and lateral scrub, respectively) follow from mapping the suspension geometry as

$$
\delta x=\left(\frac{\mathrm{d} x}{\mathrm{~d} z}\right) \delta z, \quad \delta y=\left(\frac{\mathrm{d} y}{\mathrm{~d} z}\right) \delta z
$$

$F_{\mathrm{s}}$ is the net suspension force based on the vertical wheel travel. If the spring or damper is not directly aligned with the wheel vertical motion (as is typically the case), then the 'principle of virtual work' can be used again to obtain $F_{\mathrm{s}}(z)$ (e.g. if $s$ is the spring deflection and $\tilde{F}_{\mathrm{s}}(s)$ is the variation of component of spring with deflection), then $F_{\mathrm{s}}(z)=\tilde{F}_{\mathrm{s}}(s) \mathrm{d} s / \mathrm{d} z$.

In equation (23), $T_{\mathrm{d}}$ is the drive torque (assumed to be generated from an inboard differential) and $\delta v$ is the change in the caster angle. Brake torques do not contribute, because they are considered as internal to the wheel-hub assembly (refer to reference [2] for further explanation on suspension modelling).

\subsection{Driveline and tyre}

All the computation is contained within the $S$ function in MATLAB. These deal with the wheel spin dynamics (four states) and a series of first-order lags (with fixed time constants) for the build-up of engine torque (one state), braking torques (four states), and in-plane tyre forces (eight states). Hence, overall there are 17 states. The $x$ and $y$ components of velocity of vehicle body, at the contact patches, including roll and pitch are used to find the longitudinal and lateral slip ratios. These are fed into the tyre model to obtain 'prefiltered' tyre forces $F_{\mathrm{p}}$, which are lagged in the generation of the actual tyre forces $F_{\mathrm{a}}$ (Fig. 3).

Force/torque balance across the wheels determines the wheel acceleration and velocities. To prevent excessive wheel-spin and subsequent numerical integration problems, some additional non-linear is added to limit the maximum wheel accelerations as described in equation (25)

$$
\delta \omega=\left(F_{4}-F_{x}\right) \cdot \frac{R_{\text {wheel }}}{I_{\text {wheel }}}
$$

where $\delta \omega$ is wheel acceleration, $R_{\text {wheel }}$ tyre radius, $I_{\text {wheel }}$ is the wheel inertia, $F_{x}$ is the longitudinal tyre forces,

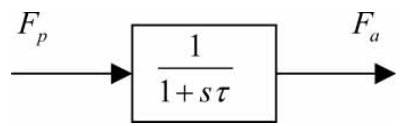

Fig. 3 Lag in the actual tyre force and $F_{4}$ is described as

$$
F_{4}=F_{\mathrm{d}} \cdot T_{\mathrm{a}}-F_{\mathrm{b}} \cdot \omega
$$

where, $F_{\mathrm{d}}$ is the drive force, $T_{\mathrm{a}}$ the fixed torque apportionment, $F_{\mathrm{b}}$ the braking force, and $\omega$ is the wheel angular velocity. By setting the maximum limit to wheel acceleration, then

$$
\delta \omega_{\max }=\frac{\left(0.25+0.5 \cdot S_{x}\right)}{\text { Time_step }}
$$

This can limit the excessive wheel-spin and at the same time improve upon numerical stability. Optional simplified antilock braking or traction control system functionality is also included to reduce the brake and drive-torque demands, when a preset slip limit is exceeded.

Basic magic formula tyre model [5] was used for the current study for rather long wavelength speed bumps (i.e. $>1 \mathrm{~m}$ ). However, for shorter wavelength speed bumps, SWIFT tyre model [6] $(>0.2 \mathrm{~m})$ or FTire model [7] would be more appropriate.

\subsection{The driver model}

There is a choice of closed-loop [8] or open-loop driver models. The closed-loop driver depends on a reference vector field of target directions and speeds, which couples to simple proportional - integral (PI) controllers for both steering and speed control. It gives reasonably good results without any sophisticated 'driver skills' or special 'knowledge' of vehicle dynamics. The vector field 'solves' the path and speed planning aspect of the driving task. A simple Ackerman steer provides a simple 'model' input for steering control, and the remainder of the steering control is via PI feedback compensation. Tracking to the reference speed control is entirely via PI feedback.

An open-loop driver is specified by a desired steer angle and a desired vehicle speed time-history. Thus, once again the speed control is feedback-based. However, because the desired speed is precomputed, a desired acceleration time-history is derived to again provide an approximate input into the vehicle (an equivalent torque demand), which is corrected by the PI feedback.

\section{ON ROAD VEHICLE TESTING}

The test car was equipped with a data logging system and several sensors, including the use of standard rate gyros for measurement of vehicle pitch, yaw, and roll motions. The test conducted corresponds to a vehicle negotiating a split speed bump as shown in Fig. 4. 


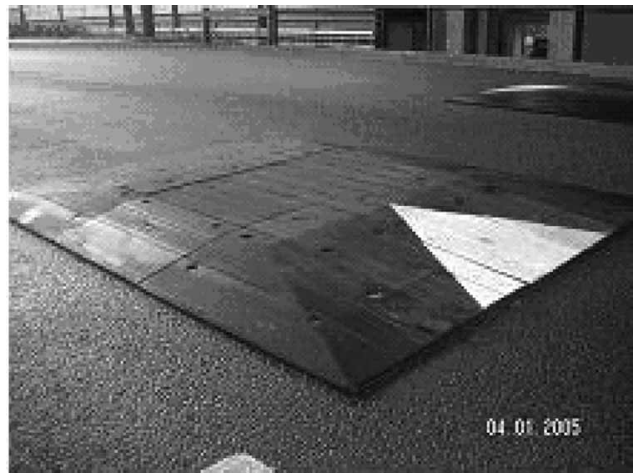

Fig. 4 The split speed bump

However, for this test, additional sensors are required, which are to measure suspension displacement on all four wheels. Owing to limited space around the suspension system, the tasks of installing all the sensors were found to be quite arduous (Fig. 5). The best position would have been to either install these parallel to the suspension strut or purely in a vertical orientation. However, this was difficult to achieve as one end of the sensor needed to be attached to the vehicle chassis and the other end should be attached to the suspension component. Because the suspension can move in vertical, lateral, longitudinal, or caster directions, to obtain a purely parallel motion to the strut or a pure vertical alignment is almost impossible to achieve. Figure 5 shows the exact installation location and alignment of the suspension displacement sensors.

Owing to the final installation positions of the sensors, a different approach in measuring suspension
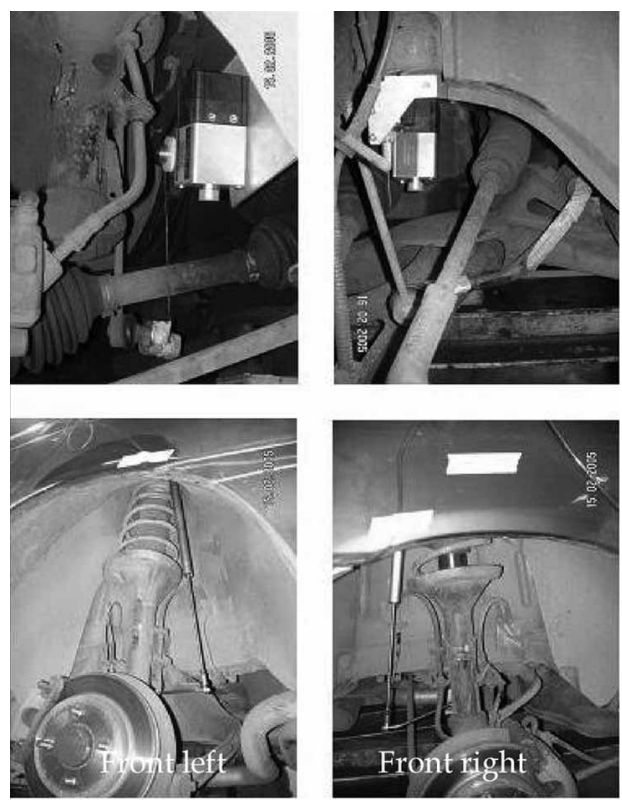

Fig. 5 Installed front suspension displacement sensors

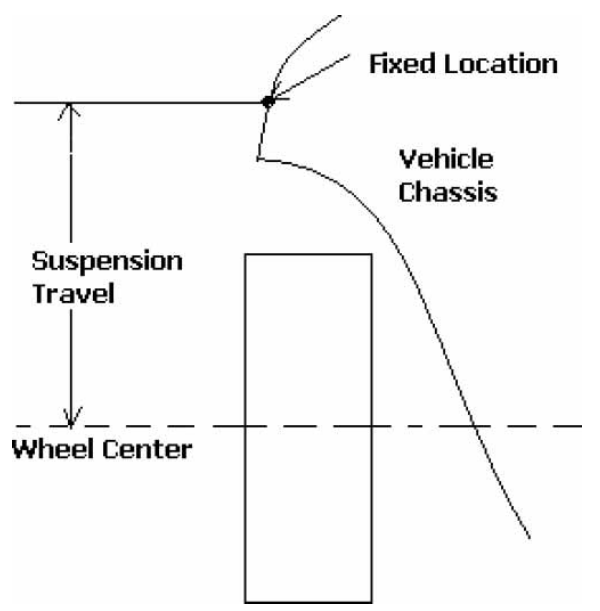

Fig. 6 Measurement of suspension travel

displacement had to be established for calibration purposes as shown in Fig. 6.

A fixed location, vertically above the wheel centre on the vehicle chassis is selected and marked. This point away from the wheel centre was set as the datum and the voltage output at this location was taken to be the base reference voltage.

Measurements were taken as the chassis lifted and the suspension is allowed to gradually fall downwards, or alternatively more weight is applied directly on the suspension. Correlation between output voltage and suspension displacement was then made.

\section{COMPARISON OF SIMULATION AND VEHICLE TEST}

The speed of the vehicle was set at $15 \mathrm{~km} / \mathrm{h}$, before it arrived at the speed bump. No brake was applied throughout the test. For this analysis, there are three characteristics of interest to be monitored. These are wheel/suspension travel, roll rate, and roll angle. When the vehicle negotiates the split speed bump, this manoeuvre translates into a single event input, deflecting the left suspension, while extending the right one.

The movements of the front suspension can be observed from Fig. 7. Without an anti-roll bar fitted, the front left suspension deflects more, when the vehicle negotiates this split speed bump, compared to the vehicle equipped with an anti-roll bar. However, the right suspension extends less with no anti rollbar. This is an expected finding due to the resistance introduced by the anti-roll bar. More importantly, the predictions made by the analytic model through simulation of exactly the same conditions show overall good agreement with the test data, as shown in the figure. A slight time delay (phase shift) is noted between the actual test data and the analytical 

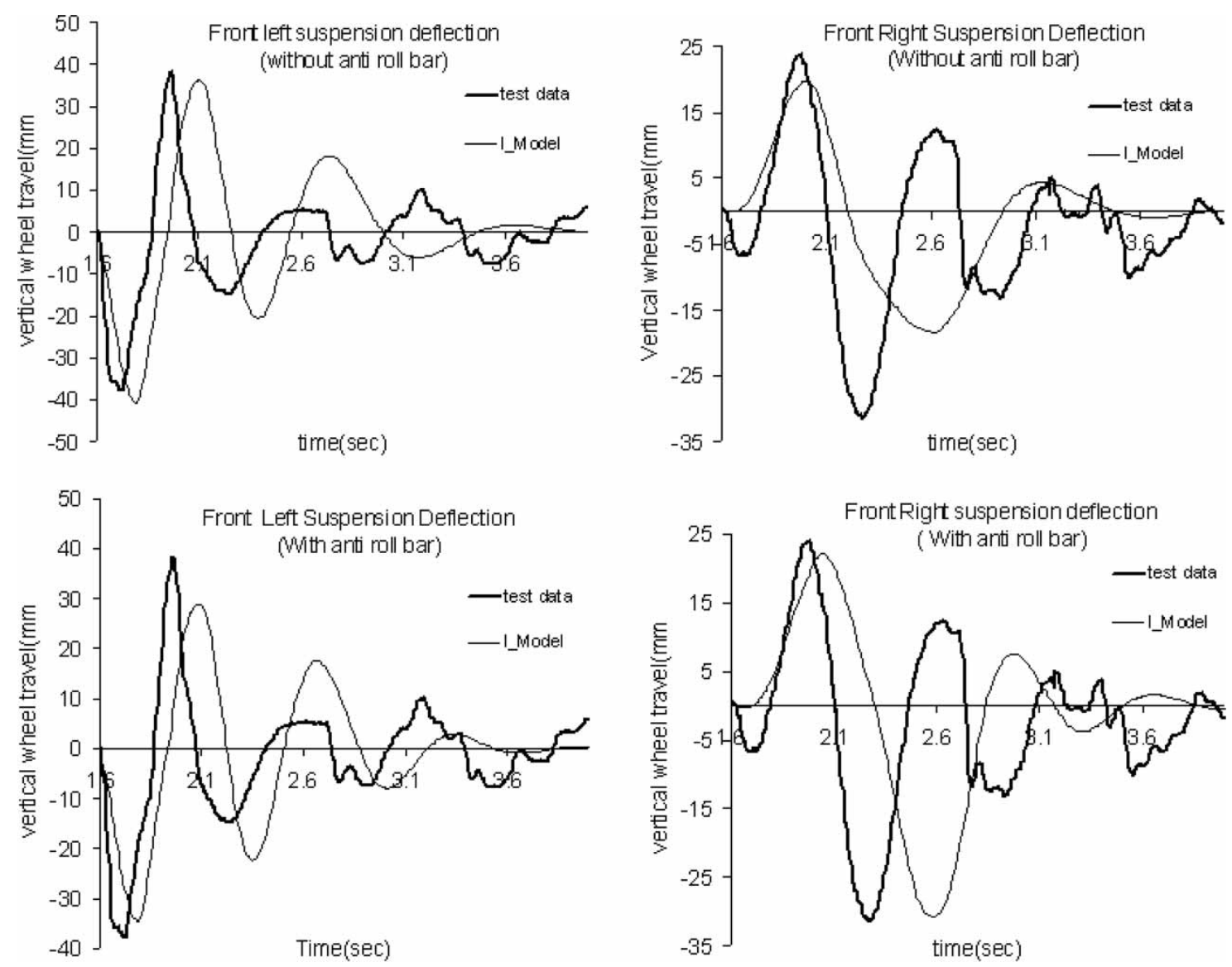

Fig. 7 Front suspension deflection

predictions. The lead in the test data is due to the vehicle having a slightly higher longitudinal acceleration, as well as the fact that during the actual manoeuvre it was noted that the right front wheel experienced a slight impact with the right-hand split (i.e. right speed bump), which cannot be quantified sufficient accurately to be included in the model simulation (which is essentially set-up as a single event). This difference is more noticeable in the graph of front right suspension travel.

The results for roll rate and the roll angle for vehicle configurations with and without an anti-roll bar indicate differences, as would be expected (Fig. 8). Even though the suspension deflection is reduced in analytical predictions with anti-roll bar, it still produces a higher roll angle and roll rate, which is not desired for
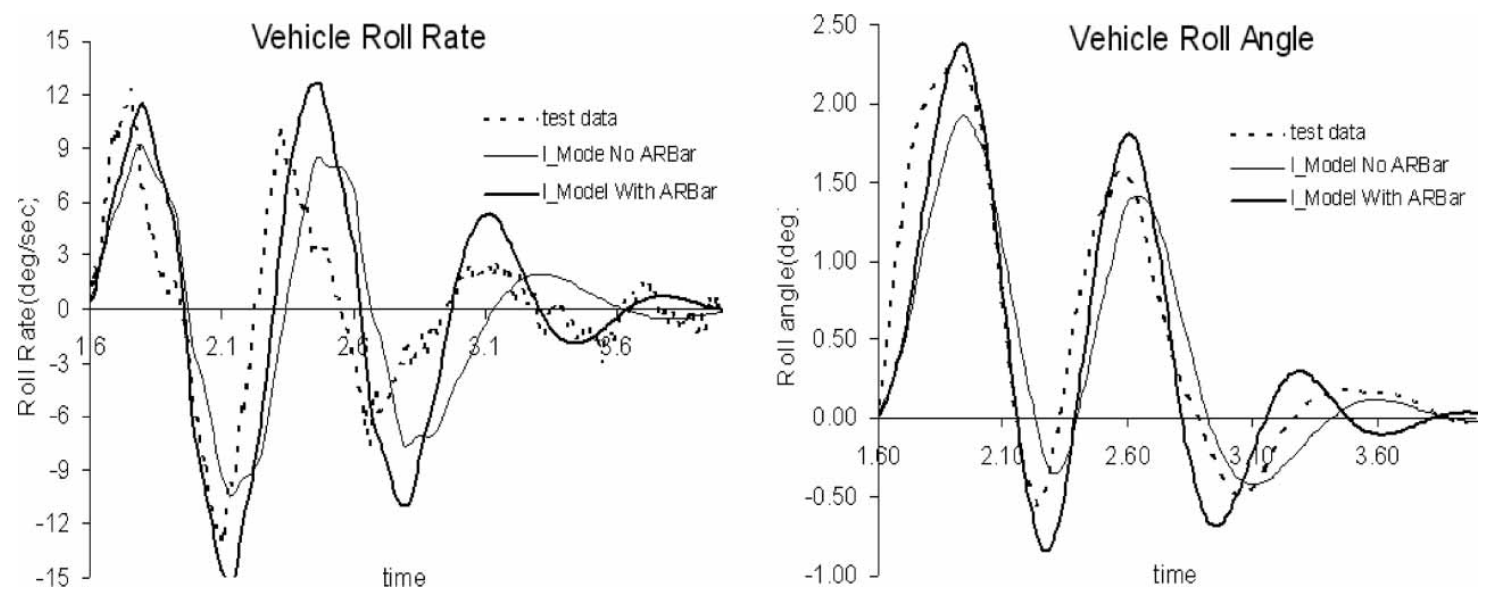

Fig. 8 Variations in the roll rate and the roll angle 
vehicle ride comfort. Thus, it is clear that the bump event is sufficient in its severity to properly activate the torsional response of the anti-roll bar.

Another important observation is the good conformity of the analytical prediction to experimental findings, except that the models do not include all sources of damping present in vehicle chassis. These include dissipation due to elastic distortions (elastokinematics) and source of dry friction in joints, which are very difficult to quantify for inclusion in the models.

\section{CONCLUSION}

The results of this preliminary study point to two main conclusions. The first concerns the importance of vehicle roll dynamics in ride comfort, which has not received the same attention as that in transient handling and vehicle stability. As in previous studies in vehicle handling, the study shows that an anti-roll bar is one of the major factors, that contributes to the overall vehicle roll stiffness. However, it also shows that for a single speed bump analysis, when the vehicle is fitted with an anti-roll bar, it demonstrates a larger body roll rate during transient conditions, compared to the vehicle model without an anti-roll bar negotiating the same speed bump. This is an undesired feature from a ride comfort viewpoint. As such manoeuvres can strictly be considered as combined ride and handling, a compromise may need to be found for development of anti-roll bar systems, which improve roll stability, while maintaining a good level of ride comfort. Hitherto, the approach in anti-roll bar design and installation has been based on handling analysis only, but with increasing single event traffic calming features on roads and greater proportion of time of drivers spent in urban areas, the issue highlighted here may become a perceived quality issue.

The second conclusion that results from this study is the affirmation of the use of simple, but sufficiently detailed, intermediate models for the study of seemingly complex ride and handling manoeuvres. Traditionally, such studies have required much more complex multi-body models, but the concordance of analytical predictions with experimental findings here point to a much less arduous approach, at least in the first instance.

\section{ACKNOWLEDGEMENTS}

Authors would like to express their gratitude to Ford Motor Company for collaborating in this study, as well as to Sirim Berhad, Malaysia for financial support.

\section{REFERENCES}

1 Sharp, R. S. Influences of suspension kinematics on pitching dynamics of cars in longitudinal maneuvering. Vehicle Syst. Dyn. Suppl., 1999, 33, 23-36.

2 Azman, M., Rahnejat, H., King, P. D., and Gordon, T. J. Influence of anti-dive and anti-squat geometry in combined vehicle bounce and pitch dynamics. Proc. Instn Mech. Engrs, Part K: J. Multi-body Dynamics, 2004, 218(K4), 231-242.

3 Katz, A. Computational rigid vehicle dynamics, 1997 (Krieger, Florida, USA).

4 Rahnejat, H. Multi-body dynamics: vehicles, machines, and mechanisms, 1998 (Professional Engineering Publishing, Bury St Edmunds and London, and Society of Automotive Engineers (SAE) co-publishers).

5 Pacejka, H. B. Tyre and vehicle dynamics, 2002 (Butterworth-Heinemann Publications, Oxford, UK).

6 Van Oosten, J. J. M. and Pacejka, H. B. SWIFT-Tyre: an accurate tyre model for ride and handling studies also at higher frequencies and short road wavelengths. Proceeding of ADAMS World Users' Conference, 2000, Orlando.

7 Gipser, M. FTire: a physically based application-oriented tyre model for use with detailed MBS and finite-element suspension models. Vehicle system dynamics, 2005, 43, 76-91.

8 Gordon, T. J., Best, M. C., and Dixon, P. J. An automated driver based on convergent vector fields. Proc. Instn Mech. Engrs, Part D: J. Automobile Engineering, 2002, 216, 329-347.

\section{APPENDIX}

\section{Notation}

$a$

$b$

CG

$\mathbf{F}_{\text {aero }}$

$\mathbf{F}_{\text {weight }}$

$\mathbf{F}_{\text {stabilizer }}$

$\mathbf{F}_{\mathrm{p}}$

$F_{x 1}, \ldots, F_{x 4}$

$F_{y 1}, \ldots, F_{y 4}$

$F_{z 1}, \ldots, F_{z 4}$

$F_{\mathrm{a}}$

$g$

$h_{\mathrm{g}}$

$\mathbf{I}_{\mathrm{G}}$

$\mathbf{I}_{x x, y y, z z}$

$\mathbf{I}_{x z}$

$\mathbf{I}_{3}$

$\boldsymbol{k}$

$k_{\text {aero }}$ front wheelbase

rear wheelbase

centre of gravity

aerodynamic force

vehicle weight

anti-roll bar resistance

prefiltered tyre forces

longitudinal tyre forces

lateral tyre forces

vertical tyre forces

actual tyre forces

gravitational acceleration

initial position of CG from the ground

inertia matrix

roll, pitch, and yaw mass moments of inertia about the vehicle centre of mass

products of inertia

$n \times n$ identity matrix

unit vector of the global $z$ direction, relative to the vehicle coordinates

coefficient of drag 


\begin{tabular}{|c|c|c|c|}
\hline$K_{\text {roll_coeff }}$ & coefficient of roll stiffness & $\mathbf{v}_{\mathrm{G}}$ & components of translational velocity \\
\hline $\mathbf{M}_{\mathrm{tyres}}$ & moment about CG due to the & $\tilde{\mathbf{z}}$ & suspension deflections \\
\hline & tyre forces & $Z_{\mathrm{rp}}$ & height of speed bump \\
\hline$M$ & vehicle mass & & \\
\hline$p, q, r$ & $\begin{array}{l}\text { angular velocity along } x, y, \\
\text { and } z \text { axes, respectively }\end{array}$ & $\begin{array}{l}\delta v \\
\delta x, \delta y\end{array}$ & $\begin{array}{l}\text { change in caster angle } \\
\text { contact patch forward progression }\end{array}$ \\
\hline $\mathbf{r}_{\mathrm{G}}$ & $\begin{array}{l}\text { distances of the contact } \\
\text { patches from CG }\end{array}$ & & $\begin{array}{l}\text { and lateral scrub } \\
\text { suspension vertical travel }\end{array}$ \\
\hline$r_{1}, r_{2}, r_{3}, r_{4}$ & $\begin{array}{l}\text { contact patch distance from } \\
\text { CG }\end{array}$ & $\begin{array}{l}\theta_{1}, \theta_{2}, \theta_{3} \\
\dot{\theta}_{1}, \dot{\theta}_{2}, \dot{\theta}_{3}\end{array}$ & $\begin{array}{l}\text { roll, pitch, and yaw angles } \\
\text { derivative of roll, pitch, and yaw }\end{array}$ \\
\hline $\mathbf{r}_{A}\left(z_{\text {sus }}\right)$ & $\begin{array}{l}\text { kinematics term, accounting } \\
\text { for steering torque }\end{array}$ & $\varphi, \theta, \psi$ & $\begin{array}{l}\text { angles } \\
\text { roll, pitch, and yaw angles }\end{array}$ \\
\hline $\begin{array}{l}t_{r r}, t_{r f} \\
U, V, W\end{array}$ & $\begin{array}{l}\text { rear and front wheel tracks } \\
\text { longitudinal, lateral, and }\end{array}$ & $\omega_{1}, \omega_{2}, \omega_{3}$ & $\begin{array}{l}\text { body angular velocity in roll, pitch, } \\
\text { and yaw }\end{array}$ \\
\hline & vertical velocities & $\omega$ & components of angular velocity \\
\hline
\end{tabular}

